\section{Re: "Predicting Risk for Opioid Misuse in Chronic Pain with a Single-Item Measure of Catastrophic Thinking"}

To the Editor: I commend Julie Lutz and colleagues ${ }^{1}$ on their work which advocated predicting risk for opioid misuse in chronic pain with a single-item measure of catastrophic thinking from the Coping Strategies Questionnaire (CSQ). There are, however, two issues that would benefit from clarification.

First, pain catastrophizing was found to be associated with negative mood, especially the cognitive and fearful aspects of anxiety and depression ${ }^{2}$, and in these clinical states, pain catastrophizing may be confounded. In fact, when Hirsh et $\mathrm{al}^{2}$ controlled for this negative mood, pain catastrophizing minimally contributed to pain prediction. Thus, the article did not explain how primary care physicians are to interpret a single-question CSQ result in patients with anxiety and depression compared with patients without these conditions this is particularly complicated if there are no follow-up questions to probe the pain catastrophizing further.

Second, ethnic differences in pain coping is well documented, with African Americans reporting a higher level of catastrophizing among pain-free young adults ${ }^{3}$ or clinical populations. ${ }^{4,5}$ For this reason, it was not clear from the article how primary care physicians working in an ethnically diversified neighborhood can interpret a single-item questionnaire from the CSQ scale in the context of a diverse ethnic patient population. Primary care physicians attending to these ethnically diverse patients see them one after the other which may complicate diagnosis.

Ayodeji Otufowora, MB.BS, MPH Department of Epidemiology
College of Public Health and Health Professions College of Medicine

University of Florida, Gainesville, FL.

The author has no conflicts of interest. The author is supported by the Dean's office, College of Public Health and Health Professions and the Department of Epidemiology, University of Florida; and thankful to his Research Mentor Dr. Linda Cottler for her support.

\section{References}

1. Lutz J, Gross R, Long D, Cox S. Predicting risk for opioid misuse in chronic pain with a single-item measure of catastrophic thinking. J Am Board Fam Med 2017;30:828-31.

2. Hirsh AT, George SZ, Riley JL, Robinson ME. An evaluation of the measurement of pain catastrophizing by the coping strategies questionnaire. Eur J Pain 2007;11:75-75.

3. Hastie BA, Riley JL, Fillingim RB. Ethnic differences in pain coping: factor structure of the coping strategies questionnaire and coping strategies questionnaire-revised. J Pain 5 2004;6:304-16.

4. Jordan JM. Effect of race and ethnicity on outcomes in arthritis and rheumatic conditions. Curr Opin Rheumatol 1999;11:98-103.

5. Jordan MS, Lumley MA, Leisen CC. The relationships of cognitive coping and pain control beliefs to pain and adjustment among African-American and Caucasian women with rheumatoid arthritis. Arthritis Care Res 1998;11:80-88.

doi: 10.3122/jabfm.2018.03.170463

The above letter was referred to the author of the article in question, who offers the following reply. 